\title{
Improved Processing Technique for Preparation of Non-Oriented Electrical Steels with Low Coercivity
}

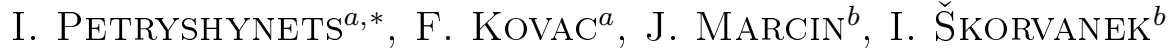 \\ ${ }^{a}$ Institute of Materials Research SAS, Watsonova 47, 04001 Košice, Slovakia \\ ${ }^{b}$ Institute of Experimental Physics SAS, Watsonova 47, 04001 Košice, Slovakia
}

In order to improve soft magnetic properties of vacuum degassed NO steels, an adjusted temper rolling process for development of particular textures $\{100\}<0 \mathrm{vw}>$ was used. The main idea here relies on a deformation-induced grain growth, which promotes preferable formation of the grains with desired orientation. Two vacuum degassed NO steels were chosen as an experimental material. In both cases, a coarse or columnar grained microstructure, with pronounced intensity of cube and Goss texture components, was achieved during a continuous final annealing. The obtained microstructure leads to a significant decrease of coercivity, measured in DC magnetic field. The coercivity of steel with silicon content 2.4 wt.\% decreased from $42 \mathrm{~A} / \mathrm{m}$ to $17 \mathrm{~A} / \mathrm{m}$. Even more remarkable improvement of the soft magnetic properties was observed for the steel with Si $0.6 \mathrm{wt} . \%$, where the coercivity value dropped from $68 \mathrm{~A} / \mathrm{m}$ to $12.7 \mathrm{~A} / \mathrm{m}$.

DOI: $10.12693 /$ APhysPolA.126.182

PACS: 61.72.-y, 61.72.Cc, 81.40.Ef, 75.50.Vv

\section{Introduction}

Non-oriented electrical steels are iron-silicon alloys with varying silicon contents, which have similar magnetic properties in all directions in the plane of the sheet and are typically used as core parts in a variety of electrical rotating equipment. Their good soft magnetic characteristic strongly rely on the ability of technological processes to precisely control the grain size and texture, as well as chemistry of the final steel sheets products [1].

The processing of NO steel comprises hot rolling, cold rolling, final annealing and coating. During the annealing a deformation induced grain growth and elimination of residual stresses take place $[2,3]$. The final annealing of this steel, according to the norm which is used in industrial conditions, has some disadvantages from the point of view of deformation-induced grain growth. The main detrimental effect follows from limitation of heating rate during annealing, that leads to early recovery processes in the temper rolled NO steel [4]. This in turn lowers the driving force of deformation-induced grain boundary motion, before the optimum temperature is achieved. Moreover, the whole industrial treatment process lasts approximately 10 hours according to the industrial norm. Before final continuous annealing, the NO steel passes through high intensity cold rolling reduction (more than $75 \%$ ). The recrystallization process of highly deformed ferrite grains takes place during the annealing process. This is the limiting factor, which makes impossible the use of deformation induced grain boundary motion phenomena for grain growth development, in this particular case.

The present paper is focused on use of deformationinduced grain boundary motion mechanism during dynamical continuous annealing process of NO steels. The

*corresponding author; e-mail: ipetryshynets@imr.saske.sk aim of the work is to develop a large grained microstructure with increased intensity of "Cube" $\{100\}<0 v w\rangle$ and/or "Goss" texture components.

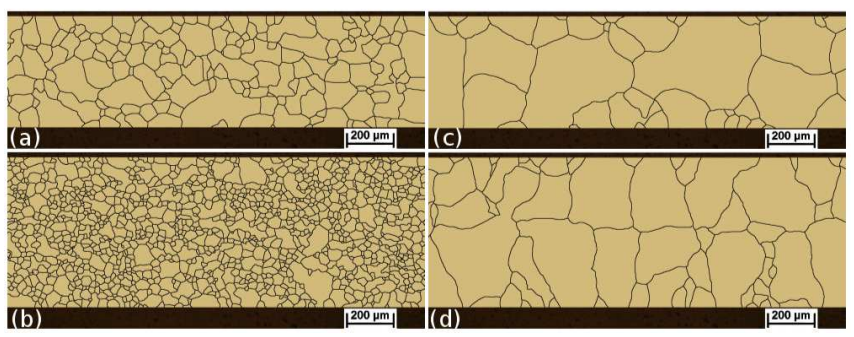

Fig. 1. Microstructure: a) and b) steels FH and FL after industrial annealing, c) and d) steels FH and FL after laboratory annealing at $950^{\circ} \mathrm{C} / 5 \mathrm{~min}$ with $4 \%$ of deformation.

\section{Experimental procedure}

As experimental material, two vacuum degassed NO steels FH and FL were used with the following chemical composition $\mathrm{C}=0.0033, \mathrm{Si}=2.4, \mathrm{Mn}=0.23, \mathrm{P}=0.008$, $\mathrm{Cu}=0.013, \mathrm{Al}=0.37$ wt. $\%$ and $\mathrm{C}=0.0053, \mathrm{Si}=0.6$, $\mathrm{Mn}=0.24, \mathrm{P}=0.123, \mathrm{Cu}=0.014, \mathrm{Al}=0.025$ wt. $\%$ respectively. The steels were taken from industrial line after final continuous annealing and then were treated under laboratory conditions. This treatment included the temper rolling reduction at the elevated temperature up to $250^{\circ} \mathrm{Cand}$ final annealing at $900^{\circ} \mathrm{Cand} 950^{\circ} \mathrm{C}$ with holding time of $300 \mathrm{sec}$ in pure hydrogen $\mathrm{H}_{2}$ atmosphere. The thickness rolling reductions were $2 \%, 4 \%, 6 \%$ and $8 \%$, respectively.

The coercive force of the steel was measured by commercial "Oersted type" coercivity meter KPS-lC, using samples with the dimensions of $3 \mathrm{~cm} \times 1 \mathrm{~cm}$. Measurements of the full quasistatic hysteresis loops for the samples with lowest coercivity values (sample dimension $10 \mathrm{~cm} \times 0.5 \mathrm{~cm}$ ) were performed by using Forster type $B-H$ loop tracer. 
Chosen microstructure states were subjected to EBSD analysis of crystallographic orientations of grains.

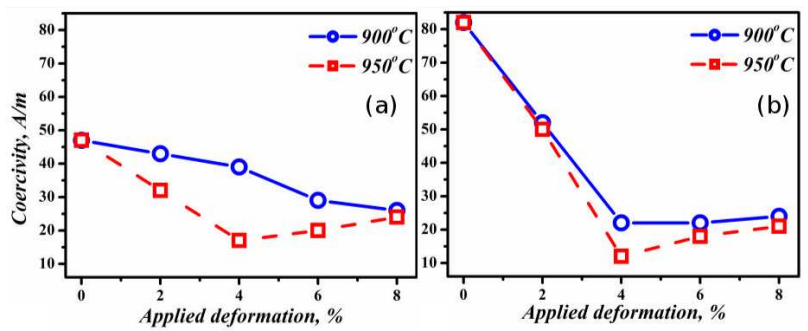

Fig. 2. Measured values of coercivity in DC magnetic field, a) - FH steel, b) - FL steel.

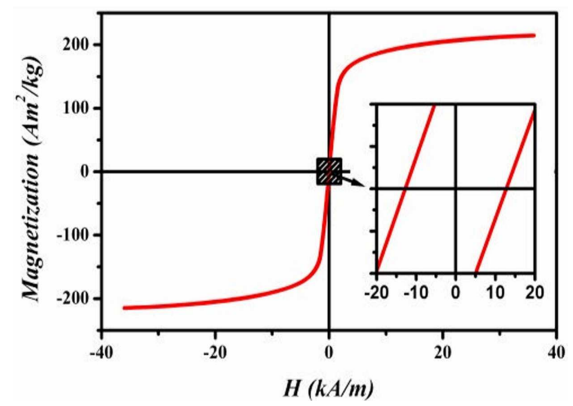

Fig. 3. Hysteresis loop of sample FL with $\varepsilon \sim 4 \%$ deformations, annealed at $950{ }^{\circ} \mathrm{Cfor} 5 \mathrm{~min}$.

\section{Result and discussion}

Microstructure of the steels FH and FL, received from the industrial line, is presented in Fig. 1a and 1b, respectively. The mean grain sizes in the samples $\mathrm{FH}$ and FL are $d=83 \mu \mathrm{m}$ and $d=27 \mu \mathrm{m}$, respectively. The coarse grained microstructure of FH material, which was achieved after temper rolling with $4 \%$ of deformation and subsequent annealing at $950^{\circ} \mathrm{C} / 5 \mathrm{~min}$ is shown in Fig. 1c. As can be seen in Fig. 1d, after similar thermo-mechanical treatment conditions, the columnar microstructure was obtained in the case of FL steel. Figure 2 presents the dependence of measured coercivity $\left(H_{C}\right)$ on the applied deformation and annealing temperature. The minimum value of $H_{C}$ for the steel FH reached $17 \mathrm{~A} / \mathrm{m}$ and in case of the steel FL it was further reduced to $12.7 \mathrm{~A} / \mathrm{m}$. This low value of coercivity was confirmed also by the quasistatic hysteresis loop measurements as can be seen from Fig. 3. The lowest value of coercivity corresponds to optimal microstructure which is presented in Fig. 1c and 1d. The results obtained from the EBSD measurements of FL samples, which present intensities of particular crystallographic texture components in the as received state and after the application of $4 \%$ rolling deformation, with the subsequent annealing at $950{ }^{\circ} \mathrm{Care}$ shown in Fig. 4a and 4b, respectively. In order to describe the texture state in the investigated materials, three texture fibers were chosen. The first one is the $\lambda$-fiber, describing the so called rotating cube texture component $<100>\| \mathrm{ND}$ (where ND is the normal direction), the second one is the $\gamma$-fiber that describes the deformation texture component $<111>\| \mathrm{ND}$ and the third texture component is the $<110>\| \mathrm{ND}$, that can be described by the $\xi$-fiber. All three fibers can be found in the section of the Euler space, taken at $\phi_{2}=45^{\circ}$. Density profiles, taken along these texture fibers, are presented in Figs. $4 \mathrm{a}$ and $4 \mathrm{~b}$. As one can see, the laboratory thermomechanical treatment led to increased intensity of the favorable cube (100)[0vw] and Goss (110)[001] texture components and to a decrease of the unwanted (111) [0vw] deformation component.

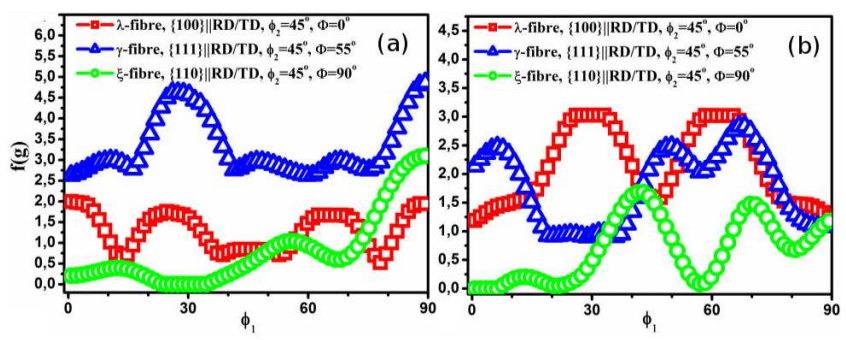

Fig. 4. Orientation density profiles taken at $\phi_{2}=45^{\circ}$ ODF's section, $\lambda$-fiber, $\gamma$-fiber and $\xi$-fiber, representing texture in FL material a) in as received state and b) after applied temper rolling and annealing at $950^{\circ} \mathrm{Cfor}$ 5 min.

\section{Conclusions}

We have shown that a large grained microstructure can be achieved in isotropic electrotechnical steels by using a deformation induced ferrite grain growth during the final annealing. The final microstructure exhibits a pronounced intensity of the cube and Goss texture components. Such a microstructure and texture state leads to a significant decrease of coercivity values, measured in DC field. In the case of steel with silicon content of $2.4 \mathrm{wt} . \%$, the coercivity decreased from $42 \mathrm{~A} / \mathrm{m}$ to $17 \mathrm{~A} / \mathrm{m}$. Even more remarkable improvement of the soft magnetic properties was observed for the steel with $\mathrm{Si} 0.6 \mathrm{wt} . \%$, where the coercivity value dropped from $68 \mathrm{~A} / \mathrm{m}$ to $12.7 \mathrm{~A} / \mathrm{m}$.

\section{Acknowledgments}

This work was carried out within the framework of the project "High strength electrotechnical composite steels", which is supported by the Slovak Research and Development Agency under the contract No. APVV - 0147 11. This work was also partially supported by the Slovak Grant Agency VEGA, project No. 2/083/13

\section{References}

[1] D. Steiner Petrovic, B. Markoli, M. Ceh, J. Magn Magn. Mater. 322, 3041 (2010).

[2] W. Lin, J Kuo, Mater. Sci. Forum 558-559, 1121 (2007).

[3] K. Murakami, J. Tarasiuk, H. Réglé, B. Bacroix, Mater. Sci. Forum 467-470, 893 (2004).

[4] R. Kočiško, P. Gavendová, J. Bidulská, M. Vlado, J. Bacsó, L. Némethová, Chem. Listy, 105, 526 (2011). 